\title{
O mito samurai no imaginário do Japão: homens e deuses na trama dos sentidos
}

\author{
Milton de Souza Coelho' \\ Felipe da Silva Triani \\ Felipe Columá ${ }^{3}$ \\ Leandro Nogueira Salgado Filho ${ }^{4}$ \\ Yara Cerqueira Montenegro Osorio ${ }^{5}$ \\ Nilda Teves Ferreira ${ }^{6}$
}

\section{RESUMO}

O estudo indica que os japoneses ressignificaram a imagem do samurai na era Meiji. Esse artifício mostrou-se eficiente para unificar a nova identidade japonesa dentro e fora do Japão com foco no Yamato Damashi ${ }^{7}$, cuja força, mesmo fora do Japão, manteve o sentimento de pertença. $\mathrm{O}$ estudo indica que esse sentimento renova-se com a prática de artes marciais como o karatê que, mesmo esportivizado, mantém vivos os valores, os ritos e os rituais que reforçam a crença subjetiva numa origem comum.

Palavras-chave: Arte marcial. Karatê. Esporte. Ética

1 Doutor de Educação Física. Professor da Universidade Federal do Rio de Janeiro (UFRJ). Rio de Janeiro/Rio de Janeiro, Brasil. E-mail: miltsc@gmail.com

2 Mestre em Humanidades, Culturas e Artes. Docente do curso de Educação Física na Faculdade Gama e Souza (FGS). Rio de Janeiro/Rio de Janeiro, Brasil. E-mail: felipetriani@gmail.com

3 Doutor em Educação Física. Professor do Centro Universitário Augusto Motta (UNISUAM). Rio de Janeiro/Rio de Janeiro, Brasil. E-mail: jorge.columa@gmail.com

4 Doutor em Educação Física. Professor associado da Escola de Educação Física e Desportos da Universidade Federal do Rio de Janeiro (EEFD-UFRJ). Rio de Janeiro/Rio de Janeiro, Brasil. E-mail: leandro.nogueira@gmail. com

5 Doutora em Educação Física. Professora adjunta do Centro Universitário Celso Lisboa (UCL). Rio de Janeiro/ Rio de Janeiro, Brasil. E-mail: yara.osorio@gmail.com

6 Doutora em Educação Brasileira. Professora aposentada da Universidade Federal do Rio de Janeiro (UFRJ). Rio de Janeiro/Rio de Janeiro, Brasil. E-mail: nilda.teves@gmail.com

7 Yamato Damashii - pode ser traduzido como Espírito Samurai; remete ao Japão antigo.

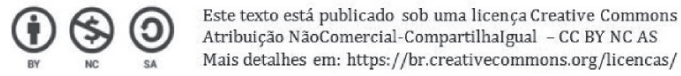


The samurai myth in Japan's imaginary: men and gods in the plot of the senses

\begin{abstract}
The study indicates that the Japanese resignified the image of the samurai in the Meiji era. This device proved effective in unifying the new Japanese identity within and outside Japan with a focus on Yamato Damashi, whose strength even outside Japan, maintained a sense of belonging. The study indicates that this feeling is renewed with the practice of martial arts such as karate, which, even when sporting, keeps alive the values, rites and ritual that reinforce subjective belief in a common origin.
\end{abstract}

Keywords: Martial arts. Karate. Sport. Ethic

\title{
El mito samurai enelimaginario de Japón: hombres y diosesenla trama de los sentidos
}

\section{RESUMEN}

El estudio indica que los japoneses resignificaron la imagen del samurai em la era Meiji. Este artificio se mostró eficiente para unificar la nueva identidad japonesa dentro y fuera de Japón con foco en el Yamato Damashi, cuya fuerza, incluso fuera de Japón, mantuvo el sentimiento de pertenencia. El estudio indica que ese sentimiento se renueva com la práctica de artes marciales como el karate que, aun esportivizado, mantiene vivos los valores, los ritos y rituales que refuerzan la creencia subjetiva en un origen común.

Palabras-clave: Arte marcial. Karate. Deporte. Ética

\section{INTRODUÇÃO}

"Os deuses são aqueles que sabem da morte, mas são imortais; o animal é aquele que é mortal, mas desconhece a morte; o homem é aquele que sabe da morte e é mortal".

Arthur Schopenhauer

O sentido da trama das artes marciais no Japão encontra-se visceralmente ligado à rede de sentidos construída pelo povo japonês para se autoidentificar e explicar o seu passado. A memória recente do Japão mostra indícios do modo exótico como o povo japonês se percebia até os anos 60 do século XX (SAKURAI, 2007).

Num quadro em que predominavam as dificuldades de divulgação de pesquisas científicas sobre as origens do povo japonês, reinavam crenças populares, cuja força conferia uma enorme singularidade ao imaginário daquele povo. A força desses referenciais 
era tão grande que a escola, ignorando a "verdade" da ciência, concedia lugar de prestígio ao ensino das crenças. Sakurai (2007, p. 47) observa que:

[...] as crianças japonesas aprendiam, por gerações e gerações seguidas, que eram descendentes de Amaterasu, a deusa do sol. Ela, a deusa mãe, teria dado origem a toda a linhagem do povo japonês que descende diretamente desse tronco divino. A mensagem embutida nessa mitologia é a de que os japoneses são diferentes de todo o resto do mundo pela sua origem divina e, mais ainda, que são homogêneos do ponto de vista racial e cultural.

Esse conjunto de crenças começou a ser abalado e combatido com a derrota do Japão na segunda guerra mundial, fato que marcou o fim desse ciclo, iniciado nas reformas da era Meiji (1868). Isso obrigou os japoneses a saírem de seu isolamento, forçando-os a repensar sua autoimagem e posição no mundo (SAKURAI, 2007, p. 47). Além disso, o intenso diálogo com o ocidente contribuiu para deslocar a figura do imperador da condição de enviado divino para a de um simples representante do país.

No Brasil, essa derrota do Japão teve um efeito adverso, já que a crença na figura divina do Imperador impediu que alguns imigrantes japoneses, influenciados por esse imaginário, aceitassem a derrota do país e a queda da divina figura do Imperador Hihoito (DEZEM, 2005).

Nesse viés, o grupo Sendo Remnei, formado por cerca de 60 mil homens sob o comando do coronel Kikawa, perseguiu os makegumi (derrotistas) porque aceitavam a derrota do Japão como noticiava o rádio (MORAIS, 2000).

As ações dessa organização, que foram retratadas por Morais (2000) no livro "Corações sujos", contribuíram para o aumento à rejeição dos japoneses naquele período.

Os membros dessa organização, quando capturados, defendiam com tanta determinação seus ideais que aceitavam com serenidade a tortura sem reclamar. Isso mostra a têmpera desses japoneses e a força do Yamato Damashii (espírito japonês), cujos traços sobrevivem nas artes marciais.

Só não aceitavam a ofensa ao seu imperador (Hirohito) e à bandeira do Japão, vistos como símbolos sagrados do Japão.

Nessa perspectiva, a única força que conseguia dobrar esses corpos empedernidos era o fumie, espécie de tortura que exigia que os japoneses pisassem na bandeira do Japão ou na foto do imperador. Esse ato era considerado por eles tão abominável que, segundo a crença do grupo, só a morte poderia aliviá-los desse "pecado". Para redimirem-se do "ato" indigno, praticavam o seppuku (corte do estomago) para resgatar a sua honra.

Assim, observa-se que o peso da explicação da origem divina do imperador sofreu uma débâcle, mas a relação do povo com o sagrado não se apagou, antes ainda, fortaleceu-se nos meandros da cultura e sobrevive nas fendas e nos fragmentos dos imaginários do povo japonês. Nesse contexto, hoje, diversos elementos culturais, entre eles as artes marciais, funcionam como catalisadores dessa memória, ligando o presente a esse passado místico, contribuindo para manterem vivas as crenças e os rituais dos filhos do sol. Dessa maneira, o presente texto analisa o entrelaçamento das artes marciais com o imaginário japonês e sua repercussão na construção do Karatê atual. 


\section{A formação do japão: o mito da raça divina e homogênea}

A mitologia japonesa, até a década de sessenta, constituía peça-chave na socialização do povo japonês que, com base em suas crenças, aceitava "naturalmente" a condição divina do imperador, cuja origem estaria atrelada à criação das ilhas japonesas ${ }^{8}$. Admitiam também que "o povo japonês fora constituído por deuses, ainda que não tão importantes quanto os da família imperial".

O mito, nesse caso, funcionava como a espinha dorsal de explicações sobre vários temas: a origem do povo, a geografia de seus territórios, as catástrofes, além de assuntos ligados ao cotidiano, tais como: hierarquia entre os sexos, separação entre vivos e mortos, orgulho das mulheres.

O mito mais relevante é o da criação, segundo a lenda (SAKURAI, 2007, p. 49),

[...] antes de tudo, havia um céu muito azul salpicado de nuvens brancas onde viviam os deuses. Estes se pareciam com os homens, embora fossem mais poderosos, maiores, mais fortes, mais ligeiros e mais bonitos. Locomoviam-se como pássaros, voando sem a necessidade de colocar os pés no chão. Sobre o mar, não havia qualquer ilha e a terra propriamente dita ainda existia. Num dia qualquer, os deuses tomaram a decisão de criar o mundo, confiando a execução da tarefa a dois jovens deuses: Izanagi e Izanami.

Os artistas japoneses retratam Izanagi como um jovem musculoso de cabelos e barbas fartas. Nas pinturas, seu corpo aparece sempre coberto por um manto azul. Izanami é retratada como uma jovem de tez suave e cabelos longos. Representa a mais perfeita imagem da beleza oriental; seu corpo aparece sempre envolvido num vestido branco.

Feitos um para o outro, teriam recebido as bênçãos dos deuses para se casarem. Chegando ao seu lugar de destino, Izanagi, com sua espada dourada, remexeu a água do mar, e da espuma fez surgir a terra. Gostaram do lugar, e ali decidiram ficar. Izanami, a deusa, propõe a Izanagi o casamento e ele aceita, desposando-a. Felizes, aguardam pelos belos filhos que haveriam de ter, conforme a promessa dos deuses.

Ocorre, contudo, uma tragédia: em lugar de belos filhos concebem monstros. Desorientados, rejeitam os filhos e recorrem aos deuses para entender o que ocorrera. Vem, então, a dramática explicação:

É o homem que deve pedir a mulher em casamento. Essa é a vontade dos céus, eis porque vocês não têm os belos filhos prometidos. Vocês devem manter a regra da antiga moral. Encabulados e perplexos os deuses voltam então para a sua morada (SAKURAI, 2007, p. 50).

Após um longo silêncio, Izanagi, o deus, volta-se para Izanami, a deusa, e Ihe propõe casamento. Izanami aceita, e como recompensa pela obediência às regras morais é abençoada com lindos filhos.

8 “O relato dessa criação mitológica está compilado no documento intitulado Registros dos assuntos antigos, datado de 1712" (SAKURAI, 2007, p. 49). 
Entre os filhos do casal, estão as ilhas japonesas com seu solo, suas rochas, montanhas, seus pinheiros, suas cerejeiras, e seus habitantes e seus animais. Mas ao conceber o último filho, o deus fogo, Izanami, queima-se tão gravemente que acaba morrendo, revelando que os deuses japoneses também são mortais (SAKURAI, 2007).

Inconformado, Izanagi desce ao reino dos mortos em busca de sua amada; perseguido pelos mortos, foge a salvo graças à intervenção de três pêssegos (frutos divinos). Retorna, então, ao mundo dos vivos, fechando, com uma pesada rocha, a entrada para esse mundo.

Sentindo-se abandonada, Izanami promete vingar-se de Izanagi: "Eu me vingarei matando num só dia mil homens da terra" Ao que ele retruca: "E eu farei nascerem, num só dia, mil e quinhentas crianças" (SAKURAI, 2007, p. 50).

Para se purificar e eliminar os males do mundo dos mortos, Izanagi banha-se na ilha de Kyushu. Das gotas que caem de seu corpo nascem seus filhos: Susanoo, o deus da tempestade e dono da planície do mar, e suas oitocentas mil ondas; Tsuki no Kami, o deus da lua, senhor do reino da noite; e Amaterasu, a deusa do sol, a quem Izanami tomando nos braços diz: "agora é a sua vez, pobre pequena" (SAKURAI, 2007, p. 51). Ungida pelo pai, Amaterasu torna-se a senhora dos céus e da terra. Anos após, a deusa recebe em seu reino a visita do irmão Susanoo, com quem fez um pacto de fraternidade.

Mas o desajeitado irmão por onde passava causava tragédia, e isso irritava a deusa que resolveu bani-lo do reino. Triste com o episódio, Amaterasu refugia-se numa caverna, prometendo não mais voltar. O mundo cai na mais profunda escuridão. Os deuses, depois de várias tentativas, conseguem demovê-la de sua decisão, apelando para sua vaidade, dizendo que uma deusa mais bela iria substituí-la. Curiosa, a deusa sai da caverna e depara-se com um espelho que reflete a sua beleza.

Os deuses tomam-na pelos braços, e a luz volta a brilhar sobre o mundo. Felizes com o retorno de Amaterasu, os deuses a presenteiam com uma joia. Susanoo, tentando a reconciliação; também a presenteia com uma linda espada retirada do ventre de um dragão que ele mesmo matara. Assim, a paz volta a reinar nos domínios de Amatersasu: o Japão.

Saltando da mitologia para o mundo real, essas joias tornaram-se as insígnias da casa imperial japonesa. Atualmente, o espelho fica num santuário em Ise, ilha de Honshu, dedicado a Amaterasu, é considerado o local sagrado mais importante do Japão. "A espada sagrada fica no templo de Atsuta nos arredores da cidade de Nagoya também dedicado a deusa. E a joia encontra-se no palácio imperial de Tóquio" (SAKURAI, 2007, p. 52).

Mas afinal, de que modo isso altera o espírito do povo japonês e das artes marciais?

\section{Da lenda para o mundo "real"}

A fé na existência de uma progênie dos deuses dos quais imperador e povo descendem diretamente, alimenta há milhares de anos a crença de que os japoneses são "puros", são racialmente homogêneos (SAKURAI, 2007).

Esse argumento "justificou" durante muitos anos a discriminação de okinawanos, burakumin. Eles trabalhavam em matadouros e curtumes, "eram tratados como párias no 
Japão porque lidavam com animais de sangue quente, e o budismo coloca restrições a isso" (SAKURAI, 2007, p. 54).

Okinawa, o antigo reino de Ryukyu, interagia com chineses e coreanos, o que tornava a sua cultura diferente e destoante em relação à cultura japonesa. Por isso, durante muito tempo, foram considerados não japoneses, algo que pode ter contribuído para postergar sua anexação ao Japão, que só ocorreu no século XX.

Os coreanos também eram considerados "inferiores", e, por isso, sofriam uma severa discriminação. A explicação científica para esse fato é a consanguinidade. Pois, a cidadania japonesa é baseada "no jus sanguinis e não no jus solis; japonês é quem tem ascendência japonesa, e não quem nasce no Japão" (SAKURAI, 2007, p. 54).

Esse mito de raça pura e de origem divina alimentou o espírito dos japoneses durante muitos séculos e contribuiu para a formação do Yamato Damashii, uma forma de preservação do espírito samurai, cuja força ao mesmo tempo em que unifica a cultura, fortalece a identidade e o sentimento de pertença dos japoneses à linhagem dos deuses. Vale registrar que os japoneses destacam sempre com orgulho sua vinculação à Amaterasu, deusa sol, ao passo que sua ligação com Susanoo é ocultada ou esquecida.

A trama ganha consistência na prática das artes marciais ao tecer as ligações do samurai com o Osho, título concedido aos mestres de artes marciais que, após longos anos de trabalho como samurais, recolhiam-se para se dedicarem à purificação. Assim, esse mestre cuja progênie é do Osho, atua como figura sagrada transformando a via marcial num "Do" capaz de operar a ascese ${ }^{9}$ intramundana.

Originalmente associado a qualquer forma de disciplina ou filosofia prática, o termo ascetismo significa alguém que pratica uma renúncia ao mundo com objetivo de adquirir um alto intelecto e espírito. Weber (2004), com foco na reforma protestante, opera uma distinção entre os ascetas, que podem estar situados "dentro do mundo" e "fora do mundo". Os primeiros chamados "ordinários", os outros, "extraordinários". O ascetismo "extraordinário" refere-se a pessoas que desistem do mundo para viver uma vida dedicada a purificação. Alguns mestres atingiam esse último estágio após anos de reclusão em templos budistas ou em retiros espirituais, onde levavam uma vida comparada a de um eremita.

\section{A era meiji e a reconfiguração da imagem "sagrada" do samurai}

A restauração Meiji (1868) tanto pode ser reconhecida como um marco da reorganização política e cultural do Japão, como também o momento em que o samurai despede-se da vida real para se inscrever no imaginário e na identidade cultural japonesa.

A reorganização de forças no cenário internacional obrigou o Japão a se reestruturar internamente para não sucumbir diante das grandes nações ocidentais.

Esse processo exigiu que os governantes conjugassem traços identitários com força suficiente para unificar internamente o Japão e, externamente, projetar para o mundo a identidade nipônica ligada ao novo estado nação que emergia.

9 O adjetivo "ascetismo" deriva do termo grego askesis (prática, treinamento ou exercício). 
Mas afinal, que face mostrar para o mundo? Quem realmente eram os japoneses? A explicação tendeu a valorizar os elementos tradicionais com capacidade de unificar, sensibilizar e mobilizar os japoneses em torno de uma imagem mítica que os identificassem plenamente. Recorreram, inicialmente, à figura do imperador; ele, no entanto, não conferia humanidade ao projeto, já que era divino (SAKURAI, 2007) e, portanto, considerado intocável . Passaram, então, a privilegiar a figura do samurai, mas não a do samurai comum:

[...] concreto cuja extinção o governo orquestrava, [mas sim a do samurai ideal simbólico que] "no imaginário japonês [...] havia demonstrado, durante os séculos passados, que o indivíduo mesmo sendo parte de um grupo unido e coeso, pode se destacar por sua coragem e lealdade (SAKURAI, 2007, p. 327).

Entretanto, as ações governamentais eram contraditórias. Por um lado, proibiam o uso de espadas e desestimulavam a prática ostensiva das artes marciais tradicionais, criando inclusive legislação especial para extinguir a existência real do samurai (Era Meiji - 1871); por outro, investiam no samurai idealizado e disseminavam o bushido ${ }^{10}$. Desse modo, o governo articulava a formação dos "sustentáculos do regime para os padrões ocidentais do final do século XIX" (SAKURAI, 2007, p. 328). O governo ardilosamente suprimiu do mundo real os elementos simbólicos atrelados à imagem do samurai.

A propósito, Funakoshi (1998) afirma que abandou o sonho de ser médico para não ter de cortar o birote ${ }^{11}$; contudo, para lecionar na escola primária, anos mais tarde, teve de fazê-lo.

Projetava-se, assim, não apenas para o Japão, mas para o mundo, a imagem mítica do samurai, homem íntegro, leal, perseverante, símbolo ideal para aquele país que oscilava entre o moderno e o tradicional. Essa imagem mistificada, ao mesmo tempo que se disseminava, ia sendo incorporada como ideal de vida, "naturalizando" a crença de que qualquer filho do sol poderia ser um "samurai" (SAKURAI, 2007).

Nesse contexto, dadas as condições socioculturais favoráveis da época, e sobretudo devido ao empenho dos governantes da era Meiji, a imagem de um samurai idealizado ancorado à ética do bushido cristaliza-se como representação predominante, marcando de forma indelével o espírito japonês.

A força dessa representação iria, posteriormente, justificar sacrifícios e renúncias em prol de um projeto de nação que emergia. Esse ideal seria decisivo nas vitórias militares contra a China e o Império russo ${ }^{12}$, o que reforçava essa imagem de nação forte, e

10 O bushido aproxima-se d Budo ou shido, código de honra do samura. Define um perfil de formação, em que atributos como retidão, lealdade, arrojo, disciplina, espírito de luta, entre outros, estão sempre presentes. A diferença é que o budo tem a arte marcial como um fim, enquanto o bushido a tem como meio de formação.

11 Birote é uma espécie de rabo de cavalo usado pelos samurais; simbolizava, a um só tempo, virilidade e identidade do samurai.

12 O Japão vitorioso, pelo Tratado de Shimonosequi, de 1894, além de forçar uma vultosa indenização (200 milhões de taels), obrigou o imperador chinês a entregar-lhe o controle das ilhas de Taiwan (Formosa), dos Pescadores e a região de Liaodong na Manchúria.

Em maio de 1905 foi a vez do Império Russo, derrotado na batalha naval de Tsushima pelo almirante Togo, 
aguçava cada vez mais "o 'espírito' guerreiro adormecido no país desde o século XVII" (SAKURAI, 2007, p. 330).

No âmbito das artes marciais, esse "espírito" samurai renasce, de forma marcante, por volta dos anos vinte em virtude da regulamentação oficial dessas práticas, coincidentemente, no período mais agudo do militarismo japonês.

De acordo com Sakurai (2007, p. 330), "essas artes completavam os ensinamentos das aulas de moral e cívica nas escolas, orientando os jovens sobre o caminho e a disciplina com nítida inspiração samurai".

A imagem de um samurai idealizado e da ética do bushido como ideal de conduta aparece tão ligada à cultura japonesa que torna praticamente impossível separá-las do Yamato Damashii (espírito japonês), mesmo na contemporaneidade. Um exemplo clássico da força desse espírito revelou-se com muita propriedade na atitude suicida dos kamikases na segunda guerra mundial. Ancorados nos princípios do nacionalismo japonês, eles representavam a expressão máxima desse espírito do bushido, desprezavam a morte (atitude típica do samurai) e projetavam-se contra os navios norteamericanos com seus aviões.

No pós-guerra, a energia desse "espírito" seria canalizada para a indústria, onde o espírito samurai contribuiria decisivamente para o desenvolvimento do toyotismo, um dos mais "sofisticados" subprodutos da ética do bushido.

A solidez desse imperativo ético pode ser constatada na síntese construída por Sakurai (2007, p. 327) quando observa que "se existe um ícone que se associa ao Japão, esse é o do samurai. Sua figura está na base da identidade japonesa, sendo uma referência em muitos momentos da história do Japão desde o século XIX".

A força da ética do bushido é vista não somente como força unificadora do campo das artes marciais, mas, sobretudo, como unificadora e dinamizadora da cultura japonesa. Foi, portanto, esse "espírito" de garra, vigor, lealdade e disciplina que as artes marciais trouxeram para o Brasil, pulsando no corpo e na alma dos imigrantes japoneses que aportaram por aqui no início do século XX.

\section{O samurai no imaginário das artes marciais esportivizadas}

A esportivização constitui uma forma sofisticada de converter o corpo marcial aos ideais do orientalismo ${ }^{13}$, gestado a partir da era Meiji (1868), no intenso diálogo que se inaugurou com o ocidente (SAID, 2007). Embora o orientalismo não tivesse o uso da esportivização como propósito precípuo, acabou elegendo-o como uma instituição estratégica na conformação dos corpos que doravante passaram a interagir de forma contraditória não

teve de ceder Port Arthur (situado numa baía chinesa) aos japoneses.

13 Em termos gerais, o orientalismo nada mais é do que uma maneira peculiar do ocidente olhar para o oriente. Trata-se de uma ideia que tem uma história e uma tradição de pensamento, que se sedimentou no século XIX, embora suas raízes sejam mais antigas. Os protagonistas dessa versão estereotipada do oriente são os ingleses os franceses e, sobretudo, após a $2^{\text {a }}$ guerra mundial os EUA que criaram e disseminaram uma visão peculiar do oriente. 
somente com os ideais olímpicos, mas, sobretudo, com o competitivismo. Esse compartilhamento de ideias divergentes criou um uma espécie de corpo samurai ocidentalizado e esquizofrênico, cuja centralidade somente se restaura quando dialoga com o mundo mítico e religioso do imaginário japonês.

Nesse viés, pode-se assinalar que a figura do samurai condensa duas dimensões cruciais que são: a ética e a estética, as quais, nas artes marciais constroem uma relação simbiótica com o imaginário nipônico, fonte dos sentidos/significados da cultura marcial japonesa (COELHO et al., 2016). Vale registrar que a exemplo dos gregos, o imaginário nipônico projeta para as artes marciais uma espécie de kaloghagatia, no qual o bom e o belo andam pari passu.

Essa combinação "natural" de um fazer ético/estético ancora-se em referenciais milenares da cultura marcial que se sedimentaram durante o xogunato e legitimaram-se na era Tokugawa (1603-1867), transformando o corpo marcial durante séculos numa metáfora da sociedade japonesa.

Ocorre que a ressemantização produzida pela era Meiji (1868) criou uma fissura nesse corpo marcial que, se por um lado, com a morte do samurai real, prodigiosamente simbolizada pelo filme o último samurai ${ }^{14}$ legitimou-se como proeminente referencial simbólico da cultura nipônica, por outro lado tornou-o mais suscetível às investidas do ocidente que já cedera aos ditames do orientalismo.

Nesse viés, o corpo marcial que migra para o ocidente é, acima de tudo, tributário dessa imagem de samurai reconfigurado que, tal como um cavalo de tróia ${ }^{15}$, passa, externamente, a veicular os anseios do olimpismo; enquanto que, internamente, busca uma coerência com a cultura marcial tradicional.

Isso se explica por um lado, pela sua necessidade de dialogar com o imaginário japonês que dá sentido e consistência a prática das artes marciais e, por outro, para atender aos anseios da esportivização e aos reclamos das diferenças culturais. Sob esse aspecto, Hall (2003, p.43) observa que:

A cultura é uma produção. Tem sua matéria-prima, seus recursos, seu "trabalho produtivo". Depende de um conhecimento da tradição enquanto "o mesmo em mutação" e de um conjunto efetivo de genealogias. Mas o que esse "desvio através de seus passados" faz é nos capacitar, através da cultura, a nos produzir a nós mesmos de novo, como novos tipos de sujeitos. Portanto, não é uma questão do que as tradições fazem de nós, mas daquilo que nós fazemos das nossas tradições. Paradoxalmente, nossas identidades culturais, em qualquer forma acabada, estão à nossa frente. Estamos sempre em processo de formação cultural. A cultura não é uma questão de ontologia, de ser, mas de se tornar.

14 The Last Samurai é um filme épico de guerra americano de 2003 dirigido e co-produzido por Edward Zwick, que também co-escreveu o roteiro com John Logan.

15 O cavalo de Tróia foi uma estratégia usada na Grécia pelos Aqueus para ludibriar os troianos na guerra de Tróia (1300 a.C. e 1200 a.C.). Na Íliada consta a referencia ao uso de um cavalo oco de madeira, idealizado por Odisseu, que fora usado pelos Aqueos para introduzir soldados no interior das fortificações inimigas. Oferecido de "presente" aos troianos num suposto gesto simbólico de rendição, tinha em seu interior vários soldados Aqueus. Orgulhosos da vitória sem perceber o conteúdo do "presente", os troianos foram surpreendidos e dominados pelos soldados Aqueus na calada da noite. 
Essa perspectiva, ao mesmo tempo em que rompe com a ideia de hegemonia cultural, indica que a cultura emerge como espaço de combinação de processos de reapropriação/ressignificação, ancorada nas táticas dos "fazedores" (CERTEAU, 1994) que, ao provocarem desvios das tradições, implicam o surgimento de "novos" sujeitos.

Tal reflexão nos permite compreender o cotidiano como "oficina" de reconfiguração dos sentidos e hibridização ampla ou restrita das identidades. Particularmente, no caso das artes marciais, permite analisar o processo de mudança da imagem "tácita" do samurai para a de identidade cultural flexível, porosa, sujeita a mudanças e a ressignificações.

A imagem reconfigurada do samurai mostra que o cotidiano, enquanto "oficina" de ressignificação identitária, designa o fazedor como artífice criador das novas identidades, não estabelecendo limites muito claros para as reconfigurações.

Mas se por um lado, esses limites não estão bem estabelecidos, por outro, nota-se que a interlocução com os marcos da sociedade capitalista atual (consumo) tendem a definir uma dinâmica que tende a transformar tudo em produto. Nesse viés, podemos dizer que "mais recentemente, o lucro é extraído diretamente do corpo, sem que se percam os lucros anteriores. É o corpo que nos querem vender. É a mercadoria que pretendemos comprar. O corpo virou "o mais belo objeto de consumo" (MAROUN, 2008, p.181).

Nesse contexto, observa-se que sob a designação artes marciais, ganham destaque no discurso midiático ${ }^{16}$ um conjunto considerável de "produtos" ligados a essa área, os quais vêm sendo produzidos e vendidos a diferentes consumidores, sejam eles passivos (vídeo games, animes, filmes, outros), sejam eles futuros praticantes de artes marciais.

Ocorre, assim, a apresentação da imagem de um objeto preciso: o corpo marcial, um tipo de corpo-metáfora, dotado de características especiais que de forma subliminar vai sendo vendido pela mídia como algo mágico capaz de transformar o praticante comum num ser especial, quase um "semi deus". Em paralelo, o competitivismo ao mesmo tempo em que exacerba o uso do tecnicismo na formação dos praticantes, provoca uma aceleração da formação dos praticantes (COELHO et al., 2016).

Essa lógica do capital institui uma relação outra na formação dos artistas marciais que fragiliza os preceitos sócio-históricos culturais e filosóficos das artes marciais tradicionais.

Em nome da "racionalidade", opera-se um aligeiramento da formação do corpo marcial com significativos prejuízos para a assimilação dos conteúdos ético-culturais típicos da tradição dessas artes marciais, como a ética do bushido, por exemplo. Com isso ocorre um tendência à divergência entre as dimensões da estética e da ética, que se acentuam à medida em que a formação, sobretudo, do faixa preta, afasta-se das raízes ético- religiosas tradicionais. Em outras palavras, pode-se assinalar que "se, para o [artista marcial] estético, a vida é vivida pelo instante, para o ético (...) ela é vivida no tempo. O [artista marcial] ético renuncia ao instante, a fim de se conformar com o universal" (CARDOSO, 2008, p.52).

Nesse sentido, nota-se que o dilema do mestre passa a ser a necessidade de lutar contra essa lógica de formação instituída pelo capital (que é sustentada pelas federações,

16 Ferramenta estratégica da sociedade de consumo. 
de modo geral), na qual a ordem de Kronos (SABÓIA, 2007) inscrita nos corpos estabelece a necessidade do gesto útil e o inevitável investimento na dimensão do "corpo-máquina", cujo escopo é à proficiência técnica, do gesto de menor gasto energético, uma configuração estética que não necessariamente valoriza a Kalokaghatia, ou seja, a harmonia entre o bom e o belo.

Esse processo cria, para as artes marciais, uma relação paradoxal que implica a um só tempo o flerte permanente com o olimpismo, e a necessidade de manter suas raízes mítico- religiosas para garantir o sentido da prática.

Significa afirmar que mesmo afrouxando a preservação de seus laços primordiais com a ancestralidade guerreira do samurai, a arte marcial esportivizada precisa manter essa ligação, ainda que tênue, para se revigorar e garantir a credibilidade e a legitimidade dessa prática.

Nessa perspectiva, observa-se que, embora esse processo seja de permanente tensão, a figura do mestre de artes marciais emerge como uma espécie de via de contenção, que seguindo a tradição do Osho, simbolicamente se transforma num ente sagrado, reduto de moralidade e retidão; capaz de transformar o "seu fazer" (arte marcial) numa via de ascese e purificação.

Nesse novo quadro, o mestre funciona como uma poderosa síntese que tem como base a arte guerreira do samurai e os vínculos afetivo-religiosos com o Osho, cuja força o inspira a indicar a seus "discípulos" o "Do" ou o caminho da retidão e da purificação.

Nessa vertente, o ícone samurai atua estrategicamente como uma figura, cuja virtude consiste não apenas em induzir e sedimentar as relações do praticante com o universo simbólico da cultura japonesa, mas, sobretudo, na capacidade de manter a estabilidade da identidade. Tal relação implica um diálogo que ora remete mais fortemente à materialidade do ícone samurai, ora aos limites da subjetividade que ele condensa (COELHO et al., 2016).

Na prática, emerge uma imagem dúbia de samurai reconfigurado, da qual sobressaem atributos que tanto apontam para a exaltação da sua belicosidade ${ }^{17}$, quanto para a sua ocultação em favor de uma "virtude de pura forma, de etiqueta, virtude do aparato" (SPONVILLE, 1993, p.15), imagem mistificada vendida como ideal de vida, naturalizando a crença de que qualquer filho do Sol Nascente poderia ser um samurai (SAKURAI, 2007).

Mas, afinal, o que torna essa figura sagrada? Que ancoragens podem legitimar o vínculo do samurai com a esfera do simbólico e com a religiosidade?

Acredita-se que tais inquietações remetam ao mito de criação do Japão, no qual os caminhos dos deuses se cruzam com os caminhos dos homens na trama dos sentidos da cultura japonesa (SAKURAI, 2007).

Embora não seja usual, pode-se dizer que o Japonês tem na sua conformação imaginária, e no seu "espírito", a energia e a pujança dos deuses Susanoo e Amaterasu, filhos de Izanagi, deus designado para criar e dar sentido ao mundo japonês (SAKURAI, 2007). 
Não obstante emergir do mesmo tronco, a natureza compassiva e serena de Amatersasu contrastava profundamente com o espírito indomável de Susanoo, deus denodado, talhado para os embates e para a transformação das forças erráticas da natureza.

A brandura de Amatersasu lembra o profundo apreço pela vida, pelo respeito à natureza, pelo senso estético, pela vaidade, pela polidez, ao passo que a imagem de Susanoo sugere o vigor, a garra, a determinação de um guerreiro, insinuando, desde então, uma ligação natural com a destruição e a morte.

Tido desde sempre como macho impetuoso, Susanoo causou diversos estragos nos domínios de Amatersasu, que exigiu dos deuses sua expulsão do céu. "Na terra, esse deus aventureiro mata um gigantesco dragão, casa-se com uma princesa e tem uma porção de filhos" (SAKURAI, 2007, p.52).

Desde então, os domínios do "espírito" japonês passaram a exibir de um lado, de forma conflitante, essa força divina nominada Susanoo, que vez por outra emerge das entranhas dos seus descendentes, dando vazão aos impulsos mais primitivos, como era do estilo desse deus de espírito irrequieto; e de outro, a imagem encantadora de Amaterasu, força positiva e conciliadora que desperta o senso de equilíbrio, o respeito à natureza, e o apreço pela vida.

Pode-se dizer, portanto, que simbolicamente a expressão do espírito japonês será sempre resultante da conjugação de duas forças: a de Amaterasu, que desperta a sensibilidade estética, a benevolência, a polidez, a afeição pelo supremo bem, e a de Susanoo, que desperta a impetuosidade, o vigor, a garra a determinação, o espírito de luta, a coragem, entre outros atributos que compõem e complementam a singular natureza dos japoneses.

Isso nos leva a sugerir que, embora se concorde com Eliade (1992, p. 85), quando diz que o mito será "sempre a narração de uma criação", contando como algo "começou a ser", acredita-se que ele também sempre representará, de certo modo, a realidade social do grupo que o enuncia. Ao relatar a caminhada, o caminhante, sem querer, oferece pistas sobre o seu caminhar e, sobretudo, indica que aspectos valoriza nessa viagem. Com foco na importância dos relatos como forma de descobrir as singularidades dos viajantes, Certeau (1994, p. 200) observa que:

\footnotetext{
Relatos cotidianos ou literários são nossos transportes coletivos, metaphorai. "Todo o relato é um relato de viagem - uma prática do espaço [...] as táticas cotidianas" (idem, p. 200). Essas aventuras narradas não são um suplemento aos enunciados dos pedestres, mas organizam as caminhadas. Como analisá-las se põe como questão. Vamos considerar apenas ações narrativas, que nos ajudarão a precisar formas elementares das práticas organizadoras de espaço (a bipolaridade "mapa" e "percurso", processos de delimitação e "focalizações enunciativas").
}

Tal approach ajuda a compreender as recorrentes situações de emergência da imagem do samurai como figura balizadora das práticas nas artes marciais japonesas esportivizadas e os diferentes modos de apropriação por parte dos novos samurais (praticantes de artes marciais), oferecendo pistas acerca das idiossincrasias, isto é, das maneiras de ver e de sentir do povo japonês ao longo da sua história. 
Essa figura simbólica emerge como a expressão da luta entre duas forças poderosas que o impelem a agir, transferindo para o seu cotidiano suas contradições e seus desejos sufocados. A marca identitária que o artista marcial moderno evocará simbolicamente a cada ação reviverá uma luta intestina que pode ser comparada à luta entre Susanoo e Amaterasu, perspectiva simbólica próxima à analogia feita por Freud (1930), no texto "Mal estar na Civilização" quando analisou as forças que comandam os desejos dos humanos, nominados por ele Thanatos (Morte) e Eros (vida).

Observa-se, assim, que a força do ícone samurai, cuja corporatura é tributária dos contornos construídos pelo bushido, ainda atua como um rizoma, atualizando uma relação de cumplicidade do praticante de artes marciais japonesas com essa genealogia religiosa e guerreira. Nela, torna-se visível a síntese imagética, produtora de novos sentidos, algo que nos coloca em contato com o indizível, com os mistérios da transcendência sugeridos pelos ritos e rituais dessas artes marciais como o karate.

\section{CONSIDERAÇÕES FINAIS}

O processo de reordenamento de forças no cenário internacional obrigou o Japão a reestruturar-se internamente para não sucumbir diante das grandes nações ocidentais com as quais precisava interagir. Atordoado ainda com as reformas requeridas pela Restauração Meiji (1868), o país, emergindo de um longo processo de isolamento, singularidade da era medieval japonesa, precisava não apenas se abrir para o mundo, mas também definir que imagem deveria exibir para ele. Isso porque a relação com outros povos implicava a definição de um perfil de japonês que pudesse ser absorvido pelo ocidente como imagem positiva.

Para tanto, precisava reconfigurar seu perfil identitário, a fim de mostrar a face de um Japão unificado e moderno em condições de ombrear-se com as grandes nações ocidentais. O Japão precisava, enfim, constituir-se como um Estado-Nação com uma face bem definida.

Nesse contexto, verifica-se que o forte entrelaçamento das artes marciais com o imaginário japonês favoreceu a eleição da figura do samurai como protagonista, pois era a única que tinha força suficiente para mobilizar o povo japonês em torno de um ideal de cultura unificada.

Tal estratégia elevou o samurai à condição de ícone da cultura japonesa, garantindo não somente a unificação do Japão em torno da ideia de uma identidade supostamente tácita (HALL, 2003), como também servindo de base para a ressemantização dessa identidade sem perder de vista as ligações simbólicas com o contexto cultural do Japão medieval (Xogunato).

A força desse ícone confere tanta força e singularidade à cultura japonesa, que mesmo na atualidade exibe significativos compromissos com essa imagem, sinalizando ser tributário de muitos de seus hábitos e atitudes, ainda que de forma difusa e, não raro, conflitante.

Pode-se estimar a força dessa imagem pelo que produziu na têmpera dos kamikazes durante os combates. Nem a derrota do Japão na Segunda Guerra Mundial, que contribuiu 
para o deslocamento da figura do imperador da condição de enviado divino para a de um simples representante do país, conseguiu destruir a força do mito samurai, que, longe de ser apagado do imaginário japonês, permanece bastante forte ainda na literatura, nos mangás, nos filmes, animes e jogos. Também na indústria essa imagem ajudou a revigorar o espírito dos japoneses que, graças a esse élan (entusiasmo), conseguiram reerguer o Japão destruído pela guerra.

Não obstante, é sem dúvida no campo das artes marciais, dentre as quais destacamos o karatê esportivizado, que essa imagem emerge pujante através dos ritos e rituais da modalidade. Ritos esses que não só modulam a formação dos praticantes, mas também revivem cotidianamente os laços com a ética do bushido, cuja influência marcou profundamente o "espírito" dos guerreiros na era medieval.

Esse ícone, não só marca a cultura japonesa, como também define os limites e as possibilidades de apropriação dos produtos culturais que os japoneses disseminam pelo mundo.

Finalmente cabe assinalar que o corpo samurai reconfigurado que emerge das artes marciais esportivizadas, mesmo cedendo aos caprichos do olimpismo, não pode abrir mão de seu intenso diálogo com o mundo mítico religioso do imaginário japonês (ritos e rituais), sob pena de tornar essa prática algo vazio, sem sentido, sem coerência e sem significado.

\section{REFERÊNCIAS}

CARDOSO, Juraciara. O tempo certo da morte digna: uma análise sobre o fim da vida à luz dos direitos fundamentais. 2008. 231 f. Dissertação (Mestrado), Programa de Pós-graduação em Direito, Pontifícia Universidade Católica do Rio de Janeiro, Rio de Janeiro, 2008.

CERTEAU, Michel. A invenção do Cotidiano. Petrópolis: Vozes, 1994.

DEZEM, Rogério. Matizes do "Amarelo": a gênese dos discursos sobre os orientais no Brasil - 1878-1908. São Paulo: SP, Editorial Humanitas, 2005.

ELIADE, Mircea. O sagrado e o profano. São Paulo: Martins Fontes, 1992.

FREUD, Sigmund. O mal-estar na civilização. Rio de Janeiro: Imago Editora, 1930.

FUNAKOSHI, Gichin. Os vinte princípios fundamentais do Karatê: o legado espiritual do mestre. 5. ed. São Paulo: Cultrix, 1998.

HALL, Stuart. Identidades na Pós-modernidade. Rio de Janeiro: DP\&A, 2003.

MAROUN, Kalila; VIEIRA, Valdo. Corpo: uma mercadoria na pós-modernidade. Psicologia em Revista, Belo Horizonte, v. 2, n. 14, p.171-186, dez. 2008. Semestral.

MORAIS, Fernando. Corações sujos. São Paulo: Companhia das Letras, 2000.

SABÓIA, Iratan Bezerra de. Cronos e Káiros: reflexões sobre temporalidade laboral e solvência social. 2007. 199 f. Dissertação (Mestrado), Departamento de Psicologia, Universidade Federal do Ceará, Ceará, 2007.

SAKURAI, Célia. Os Japoneses. São Paulo: Contexto, 2007. 
SCHOPENHAUER, Arthur. Da morte. São Paulo: Martin Claret, 2002.

SPONVILLE, André Comte (Org.). A pequena virtude. Porto Alegre: L\&pm, 1993.

WEBER, Max. Ética protestante e o espírito do capitalismo. São Paulo: Companhia das Letras, 2004.

YONEZAWA, Fernando Hiromi. Algo se move: um elogio filosófico-ético à prática do combate como arte e educação. Motriz, Rio Claro, v. 2, n. 16, p.348-358, jun. 2010.

Recebido em: Outubro/2017 Aprovado em: Dezembro/2017 